\title{
Varicella myocarditis producing congestive cardiomyopathy
}

\author{
F. T. THANDROYEN \\ M.R.C.P.
}

\author{
A. C. Asmal \\ M.R.C.P., M.D.
}

\author{
T. G. ARMSTRONG \\ M.D., F.R.C.P.
}

\begin{abstract}
King Edward VIII Hospital, and the Cardiac Unit, Department of Medicine, University of Natal Medical School, Durban, South Africa
\end{abstract}

\begin{abstract}
Summary
A 14-year-old boy with proved varicella developed severe, intractable heart failure with the clinical features of congestive cardiomyopathy. Detailed investigations failed to disclose any alternative aetiological factor. It is proposed that varicella myocarditis was the cause of the acute congestive cardiomyopathy found in this patient.
\end{abstract}

\section{Introduction}

Although cardiac involvement in varicella has been described at post-mortem in those dying from unrecognized myocarditis or from other varicella complications (Hackel, 1953; Tatter et al., 1964; Moore et al., 1969; Morales, Adelman and Fine, 1971), clinical evidence of heart involvement in this disease is extremely rare, and is usually only recognized when there are suggestive electrocardiographic changes or when cardiac failure supervenes (Vazifdar and Levine, 1952; de Medeiros Neto, de Almeida and Facchini, 1961). In patients who survive there are no reported long-term sequelae.

In this report the authors describe the development of intractable cardiac failure and acute congestive cardiomyopathy in a 14-year-old boy who was initially treated in hospital for acute varicella. It is proposed that the cardiomyopathy resulted from severe varicella myocarditis.

\section{Case report}

A 14-year-old boy was admitted to an outlying hospital with severe varicella, but without any sign of the potentially fatal complications, namely pneumonia, meningo-encephalitis or thrombocytopenic purpura. On admission there was also no evidence of cardiac involvement; specifically the patient was not in cardiac failure, there were no

Address for reprints: Dr F. T. Thandroyen, MRC Ischaemic Heart Disease Research Unit, Department of Medicine, University of Cape Town Medical School, Observatory 7925, South Africa. audible cardiac murmurs and the chest radiograph showed a normal-sized heart (Fig. 1). However, 4 days later he developed orthopnoea and paroxysmal nocturnal dyspnoea with the clinical features of congestive cardiac failure. Despite therapy with digoxin $0.25 \mathrm{mg}$ and frusemide $120 \mathrm{mg}$, both twice daily, his condition failed to improve and he was referred to King Edward Hospital, Durban.

On admission the general examination revealed the typical rash of varicella. There was pitting oedema of both legs and on cardiovascular examination, the pulse rate was 120 beats/min and the BP was $100 / 80 \mathrm{mmHg}$. The jugular venous pressure was elevated $10 \mathrm{~cm}$ above the manubrium sterni, and it exhibited the characteristic $\mathrm{cV}$ waves of tricuspid incompetence. The apex beat was hypodynamic in character and was displaced to the 6th intercostal space in the anterior axillary line. On auscultation, the murmurs of mitral and tricuspid incompetence were heard, and at the cardiac apex there was a loud third heart sound. Bilateral basal crepitations were also noted. The liver was tender, pulsatile and enlarged $10.5 \mathrm{~cm}$ below the costal margin. No additional abnormalities were detected in any of the other systems.

The posterior-anterior (Fig. 2) and lateral chest $X$-rays demonstrated biventricular and biatrial enlargement, pulmonary venous congestion and distended superior vena cava.

The ECG showed sinus tachycardia $120 / \mathrm{min}$, a frontal QRS axis of $45^{\circ}$, right atrial enlargement, flat $T$ waves in praecordial leads V4-6 and left ventricular hypertrophy by voltage criteria.

Laboratory investigations showed a haemoglobin concentration of $14 \mathrm{~g} / \mathrm{dl}$, a WBC of $6 \times 10^{\%} / 1$ and an ESR of $112 \mathrm{~mm} / \mathrm{hr}$. Serum lactate dehydrogenase was 380 i.u./l (normal values 170-340 i.u./l) and aspartate transaminase was 24 i.u./1 (normal values 3-12 i.u./l). Serum urea and complement were normal as was the urine analysis. Antistreptolysin titres done on 3 occasions over a period of 3 weeks 


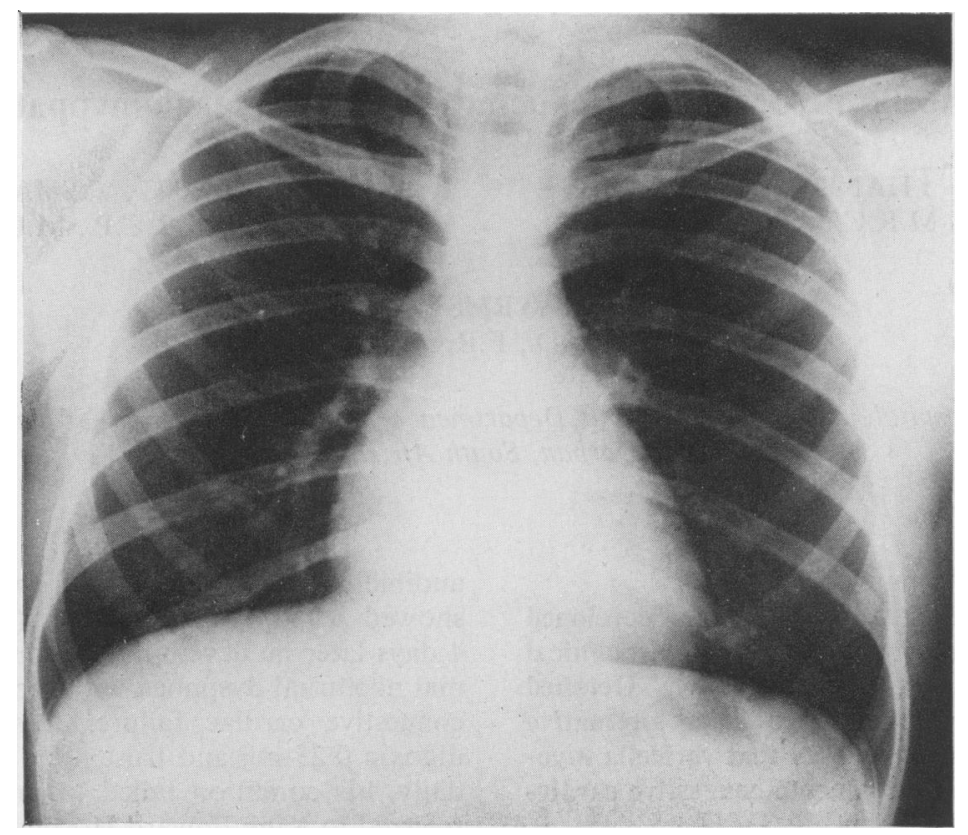

Fig. 1. Posterior anterior chest $\mathrm{X}$-ray showing-a normal cardiothoracic ratio.

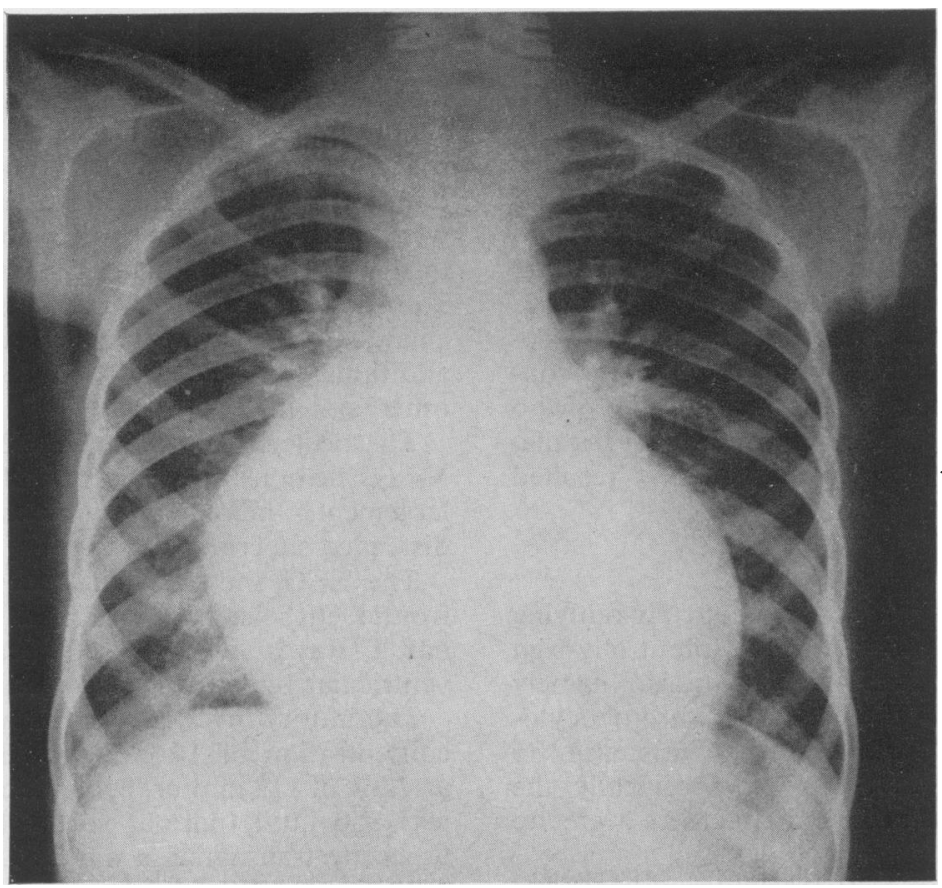

FIG. 2. Posterior anterior chest X-ray demonstrating marked cardiomegaly, pulmonary venous congestion and a distended superior vena cava. 
were normal and a throat swab failed to reveal any pathogenic organisms. The varicella complement fixation test showed a rising titre from $1 / 32$ to $1 / 128$ over a period of 2 weeks, indicating active varicella infection. Sera did not reveal positive or rising titres to adenovirus, Coxsackie virus or influenza virus.

The patient was treated with strict bed rest, digoxin $0.25 \mathrm{mg}$ daily, together with high dose oral and i.v. frusemide. As there was no resolution of heart failure, hydrallazine $300 \mathrm{mg}$ daily and isosorbide dinitrate $40 \mathrm{mg}$ daily were added but were without effect. Four months later the patient, still in cardiac failure albeit less, was discharged to an outlying hospital. On re-examination after a further 3 months, cardiac failure was still clinically evident.

\section{Discussion}

In this patient, varicella was clinically diagnosed on the basis of the characteristic rash with its typical distribution, and was confirmed by the rising varicella antibody titre.

On admission to hospital there was no evidence of heart involvement and the course of the disease was unremarkable until congestive cardiac failure developed. There was no previous history of rheumatic fever or cardiomegaly and the clinical features and laboratory investigations were not in keeping with acute rheumatic pancarditis or infective endocarditis. The authors attribute the auscultatory findings of mitral and tricuspid incompetence to functional dilatation of the atrio-ventricular valves secondary to severe myocardial damage; however, they cannot exclude direct viral involvement of the valves as suggested to occur in other forms of viral myocarditis (Burch and Colcolough, 1969). The primary diagnosis was therefore varicella myocarditis causing severe cardiac failure.

Varicella myocarditis was first reported by Hackel in 1953 who described the post-mortem findings in 7 children dying from severe complications of varicella but in none of these children had myocarditis been suspected clinically.

More recent reports have shown that varicella myocarditis may indeed be symptomatic. Moore et al (1969) described varicella myocarditis presenting as cardiac failure in 2 children under 3 years of age. Both cases responded to conventional therapy, including steroids in one case, with complete resolution of heart failure. Castleman and Kibbee (1963) described a further case of heart failure in a 30-year-old woman but varicella myocarditis was not solely responsible for the heart failure, because at post-mortem old fibrotic myocarditis together with multiple pulmonary emboli and pulmonary infarction were also found.

Although in several cases of acute viral myo- carditis progression towards cardiac enlargement and/or dysfunction has been noted (Sainani, Krompstie and Slodki, 1968; Smith, 1970; Levi et al., 1977), the authors believe that this is the first reported case of acute congestive cardiomyopathy complicating acute viral myocarditis. Furthermore, they document the first described case of varicella cardiomyopathy.

Another interesting facet to this case was the mode of presentation and its relationship to the clinical diagnosis. It is a feature of African medicine that patients frequently present to hospital at a late stage of their illness. Had this patient not been admitted initially, and had he first presented when the acute varicella infection had subsided, it is likely that a diagnosis of idiopathic congestive cardiomyopathy would have been made; a diagnosis compatible with the clinical findings and one common in the African population. This highlights one difficulty in elucidating the aetiological factors causing congestive cardiomyopathy.

In conclusion, this case is of interest because it demonstrates that, although viral infections usually run a benign course, the tendency to myocardial involvement is always present and a rare complication may be the development of congestive cardiomyopathy.

\section{Acknowledgments}

The authors are extremely grateful to Dr Timothy Noakes for criticism of the manuscript.

\section{References}

Burch, G.E. \& Colcolough, H.L. (1969) Viral valvulitis. American Heart Journal, 78, 119.

Castleman, B. \& Kibbee, B.U. (1963) Case records of the Massachusetts General Hospital. Case 15-1963. New England Journal of Medicine, 268, 488.

De Medeiros Neto, G.A., De Almeida, D.B. \& Facchini, F.B. (1961) Myocarditis associated with chickenpox treated by corticosteroids. Revista do Hospitàl das Clinicas Faculdade de Medicina da Universidade de São Paulo, $16,427$.

HACKel, D.B. (1953) Myocarditis in association with varicella. American Journal of Pathology, 29, 369.

Levi, G.F., Prots, C., Quadri, A. \& RatTi, S. (1977) Coxsackie virus heart disease and cardiomyopathy. American Heart Journal, 93, 419.

Moore, C.M., Henry, J., Benzing, G. \& Kaplan, S. (1969) Varicella myocarditis. American Journal of Diseases of Children, 118, 899.

Morales, A.R., Adelman, S. \& Fine, G. (1971) Varicella myocarditis. Archives of Pathology, 91, 29.

Sainani, G.S., Krompstie, E. \& Slodki, S.J. (1968) Adult heart disease due to the Coxsackie B infection. Medicine, 47, 133.

Smith, W.G. (1970) Coxsackie B myopericarditis in adults. American Heart Journal, 80, 34.

Tatter, D., Gerard, P.W., Silverman, A.H., Wang, C.I. \& PeArson, H.E. (1964) Fatal varicella pancarditis in a child. American Journal of Diseases of Children, 108, 88.

VAZIFDAR, J.P. \& LEVINE, S.A. (1952) Benign bundle branch block. Archives of Internal Medicine, 89, 568. 